\title{
CALLUS INDUCTION AND PLANTLET REGENERATION FROM CENTELLA ASIATICA LINN
}

\author{
*Indumathy. A, *P. Mahalakshmi. ${ }^{*}$ C. R. Bojan.
}

\begin{abstract}
Efficient plant regeneration could be obtained from the derooted nodal segments of Centella asiatica with stolen buds as the explant, when . culfured on MS medium supplemented with BAP (10 ppm) + NAA (2 $\mathrm{ppm})$.Both callus and regeneration occurred simultaneously on the same medium. Profuse rooting were obtained on MS medium fortified with NAA ( 2 ppm) from leof explants. Shoot and root proliferation were obsenved on the medium supplemented with BAP ( $5 \mathrm{ppm})$ and NAA ( 2 ppm) through subculfure. Mass propagation of plantlets were obtained through invitro culture.

Keywords: Centella Asiatica, derooted nodal segments.

Abbreviation: BAP -benzylaminopurine, NAA - naphthalene acefic acid, 2,4 - D - 2,4 - Dichlorophenoxyacetic acid, $\dot{M} S$ - Murashings and Skoog medium.
\end{abstract}

\section{Introduction}

Centella asiatica, commonly called as Indian pennywort is one of the important plants in the field of herbal medicine. Traditionally, it is used for leprosy (because of its anti-bacterial activity), gonorrhea, fever, cold. ageing problems (to delay ageing),

* Post-Groduate Department of Botany, Pachaiyappa's. College, Chennai 600030.

** Professor \& Head, Department of Botany, Pachaiyappa's College, Chennai 600030. 
eczema, psoriasis, asthma, boosting mental activity. C. asiatica has been claimed to improve memory and learning ability and to overcome the negative effects of fatigue and stress. Leaves of C. asiatica, used in India as a brain tonic, an adjuvant in the treatment of leprosy ulcers, a diuretic and for the treatment of skin diseases. This important medicinal plant, has been subjected to quite extensive experimental or clinical investigations.

The primary active constituent present in Centella asiatica is a triterpenoids which include asiaticoside, madecassoside and madsiaatic acid. A new triterpine madecassoside $220^{\circ} \mathrm{mp}$ and madecassic acid, $\mathrm{mp} 265^{\circ}$ were isolated and charecterised as 2 a, 3B, 6B - trihydroxy - 12 en - oic acid polyacetylenes (?, II, III, IV, V) were isolated.

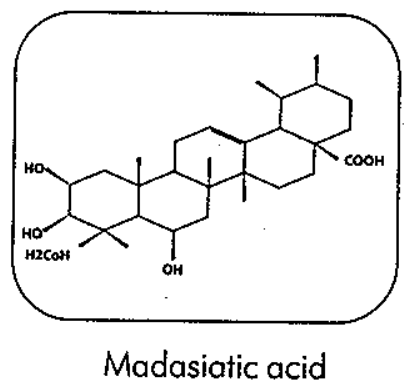

Tissue culture is the most promising field where the micro propagation of medicinal plants is very successful. Tissue culture techniques can play an important role in rapid multiplication and germ plasm conservation of Centella asiatica. Exploitation of Centella asiatica has reached its core with reference to its medicinal importance. It is promisingly a more responsive plant among other medicinal plants. The protocol reported here is a very efficient method for callus induction and plant regeneration. Large number of plantlets can be obtained through mass propagation.

\section{Materials and Methods}

The source of Centella asiatica were obtained from the damp, moist regions.( Pondicherry). They were maintained under the greenhouse conditions. The explant selection was done during early morning the explants such as derooted nodal segments with stolon bud, leat, stolon, petiole were taken and surface sterilized using standard methods. After the treatment with detergent was treated with $0.1 \%$ $(w / v)$ mercuric chloride in the LAF chamber. Then it was washed thoroughly with sterile distilled water for three to five times to remove the traces of surface adherent. The derooted nodal segments with stolon bud at one end were then sliced and 
cultured on MS medium supplemented with varying concentrations of BAP. Prior to autoclaving the $\mathrm{pH}$ of the media was adjusted to 5.8. with $0.1 \mathrm{~N} \mathrm{HCl} / 0.1 \mathrm{~N} \mathrm{NaOH}$. All cultures were maintained under a light period of 16 hours and temperature around $24 \pm 2^{\circ} \mathrm{C}$. The leaf explant with it's ventral side facing the medium were cultured on MS medium fortified with NAA ( $2 \mathrm{ppm}$ ) alone. The derooted nodal segments were also cultured on MS medium supplemented with BAP ( $4 \mathrm{ppm}$ ) and NAA ( $2 \mathrm{ppm}$ ) in combination for the regeneration and callus induction simultaneously. Later the callus segments were subcultured on MS medium fortified with NAA ( $3 \mathrm{ppm}$ ) alone. The regenerated plantlet were subcultured on MS medium supplemented with BAP (5 ppm), NAA ( $2 \mathrm{ppm})$, where both shoot and root formation was observed. The rooted plantlets were acclimatized.

\section{Results and Discussion}

At the lower concentration of BAP (i.e., $4 \mathrm{ppm}$ and $6 \mathrm{ppm}$ respectively), the initiation of leaf was delayed whereas higher the concentration of BAP (i.e., 8 ppm and $10 \mathrm{ppm}$ respectively) the leaf initiation and growth was profuse. When the derooted nodal segments with stolon bud were cultured, the elongation of stolon was quite evident on M.S medium supplemented with BAP( $5 \mathrm{ppm})$. The leaf explants cultured on MS medium supplemented with NAA ( 2 ppm) resulted in the formation of profuse rooting with root hairs on its ventral surface. The nodal segments when cultured on the MS medium fortified with BAP (4ppm) and NAA (2ppm) resulted in the formation of both shoot and callus proliferation simultaneously. The callus segments were detached from the medium and are sub cultured separately on MS medium with NAA (3ppm) . The regenerated plantlets obtained from MS medium fortified with BAP were sub cultured in the MS medium fortified with BAP $(5 \mathrm{ppm})$ and NAA (2PPM) for multiple shoot and root proliferation. These rooted plantlets were acclimatized by transferring them to a mixture of sterile sand and soil, which are covered with polythene bags and are kept under diffused sunlight for its better survival.

Sudherson, 1998 reported the mass propagation of Enicostemma axillare from leaf explant when cultured on MS medium fortified with 8-9 mM BAP.. Baburaj et al,, (2000) reported adventitious shoot formation from leaf explant without any visible callusing and the development of shoot meristemoid from the cut surface of the leaf segments when cultured on MS medium containing BAP $0.5 \mathrm{mg}^{4}$. The number of shoots formed was same when leaf explants were planted with either abaxial or adaxial side with the medium. 

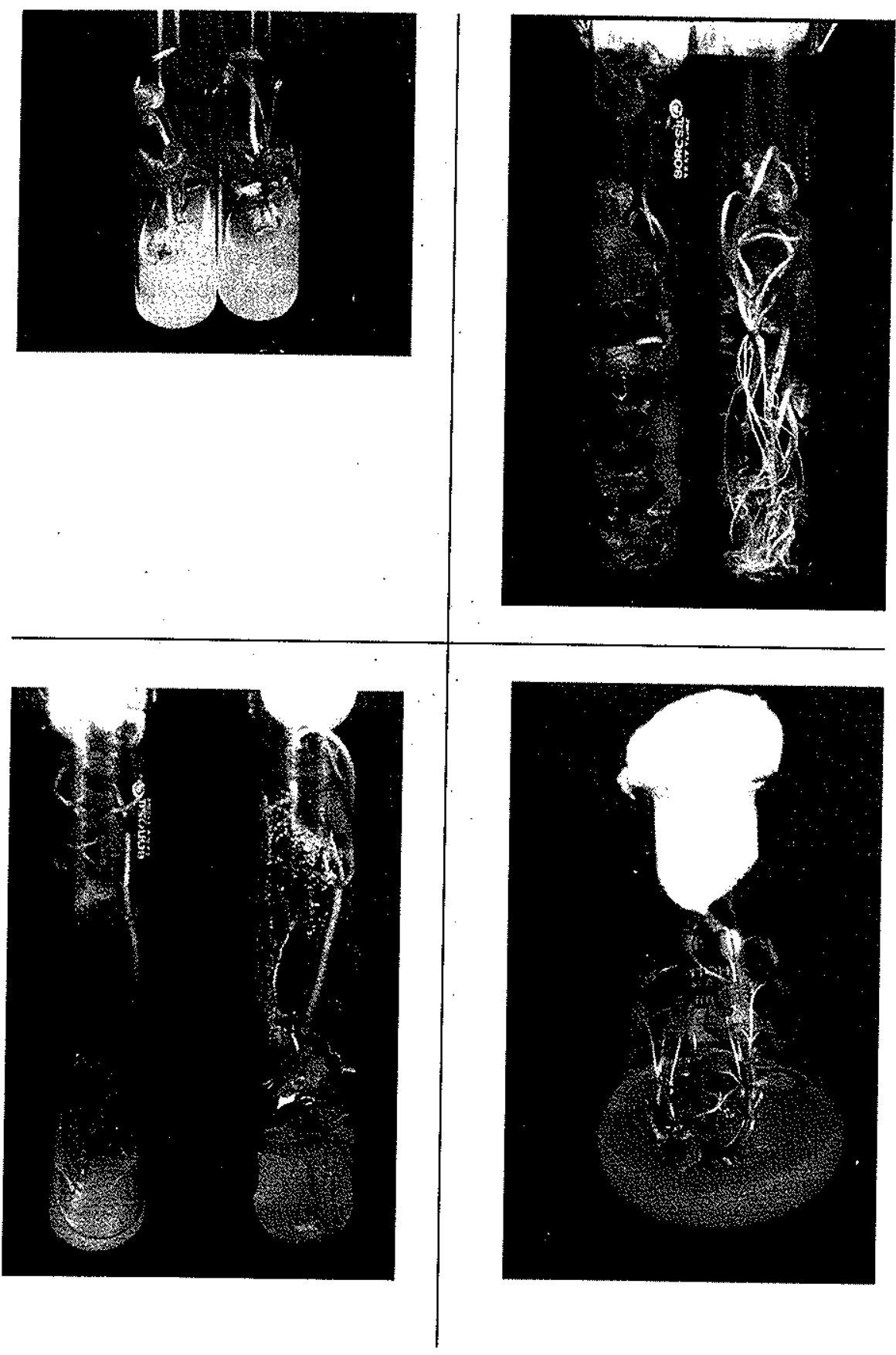


\section{References}

1. Baburai, S. P.Ravichandran and M.Selvapandian, (2000). In vitro adventitious shoot formation from leaf culture of Clerodendrum inerme (L) Gearth. Indian Journal of Experimental Biology, 38: 1274 -1276

2. Sudhersan, C.(1998) Shoot bud regeneration from leaf explants of a medicinal plant: Enicostemma axillare. Curr. Sci. 74: 1099 - 1100.

3. Patra.A, Rai.B, Rout G12, Das.P (1998) Successful plant regeneration from callus culture of Centella asiatica (Linn). Plant growth regeneration 24:1,13.16: 10 ref.

4. Josekutty.PC (1998) callus culture and micro propagation of Centella osiatica a medicinal plant. Phyton - Buenos Aries . 63:1-2,275-278; 11 ref.

5. Sucheta tripathy and Reddy.G.M. (2002) Inviro callus induction and plantlet regeneration from Indian cotton cultivars. Plant cell biotechnology and molecular biology. $3(3$ \& 4): 137.142.

6. F. Delporte, O. Mostada and J.M. Jacquemin (2001). Plant regeneration through callus initiation from thin mature embryo fragments of wheat. Plant cell tissue and organ culture. $67: 73-80$. 